Mechanisms for Precipitation Variability of the Eastern Brazil/SACZ Convective Margin

H. Ma, X. Ji, J. D. Neelin, C. R. Mechoso

April 26, 2011

Journal of Climate 
This document was prepared as an account of work sponsored by an agency of the United States government. Neither the United States government nor Lawrence Livermore National Security, LLC, nor any of their employees makes any warranty, expressed or implied, or assumes any legal liability or responsibility for the accuracy, completeness, or usefulness of any information, apparatus, product, or process disclosed, or represents that its use would not infringe privately owned rights. Reference herein to any specific commercial product, process, or service by trade name, trademark, manufacturer, or otherwise does not necessarily constitute or imply its endorsement, recommendation, or favoring by the United States government or Lawrence Livermore National Security, LLC. The views and opinions of authors expressed herein do not necessarily state or reflect those of the United States government or Lawrence Livermore National Security, LLC, and shall not be used for advertising or product endorsement purposes. 


\title{
Mechanisms for Precipitation Variability of the Eastern Brazil/SACZ Convective Margin
}

\author{
H.-Y. Ma ${ }^{1}$, X. Ji ${ }^{2,3}$, J. D. Neelin ${ }^{2}$, and C. R. Mechoso ${ }^{2}$ \\ ${ }^{1}$ Program for Climate Model Diagnosis and Intercomparison, Lawrence \\ Livermore National Laboratory, Livermore, California, USA \\ ${ }^{2}$ Department of Atmospheric and Oceanic Sciences, University of \\ California, Los Angeles, Los Angeles, California, USA \\ ${ }^{3}$ School of Atmospheric Sciences, Nanjing University, Nanjing, China
}

\footnotetext{
${ }^{1}$ Corresponding author address: Hsi-Yen Ma, Program for Climate Model Diagnosis and Intercomparison, Lawrence Livermore National Laboratory, Mail Code, L-103, 7000 East Avenue, Livermore, California, 94551-0808, USA.

E-mail: ma21@1lnl.gov
} 


\begin{abstract}
The present study examines the mechanisms for the connection between the precipitation variability in eastern Brazil and the South Atlantic convergence zone convective margin (eastern Brazil/SACZ convective margin), and the variability of lowlevel inflow on interannual time scales during austral summer. Our methodology is based on the analysis of observational datasets and simulations by the UCLA atmospheric general circulation model (AGCM) coupled to the Simplified Simple Biosphere Model.

It is demonstrated that the inflow variability is associated with the leading mode of wind variability over sub-tropical South America, and the connection is established through the mechanism of an analytic prototype for convective margin shifts proposed in previous studies. Over the eastern Brazil/SACZ convective margin, the weaker (stronger) convection tends to occur together with stronger (weaker) low-level inflows in reference to the mean easterly trades. By changing the "ventilation" effect, stronger (weaker) inflows with low moist static energy from the Atlantic Ocean suppress (promote) convection. The causal relationship is verified by AGCM mechanism-testing experiments performed in perpetual-February mode, in which low-level, nondivergent wind perturbations are imposed in a region overlapping eastern Brazil and the western Atlantic Ocean. With solely the imposed-wind perturbations acting on the moisture advection in the model equation, the AGCM can reproduce the precipitation variability in the eastern Brazil/SACZ convective margin. The capability of the AGCM in capturing such precipitation sensitivity to the low-level inflow variability also suggests that the mechanism can be applied to other regions of convective margins or to other time scales.
\end{abstract}




\section{Introduction}

Key features of the summertime precipitation in South America include strong monsoon convection in central Amazonia, and the northwest-southeast oriented band of convective activity known as the South Atlantic Convergence Zone (SACZ), which extends from eastern Brazil into the adjacent Atlantic Ocean. Along the eastern edge of the strong convection zones is a transition toward the low-precipitation region of the southern tropical Atlantic trades. On interannual time scales, summertime precipitation in South America shows strong variability from the eastern Brazil to La Plata Basin (Nogués-Paegle and Mo 2002). Such variability can result in drought and flood events, which have significant impact on human activity and economy. The better understanding of the mechanism that produces such variability is crucial to improve predictions of those important hydrological events.

The review article on American monsoon systems by Vera et al. (2006) outlines the consensus view that several factors can influence the variability of precipitation over the eastern Brazil and SACZ region: sea surface temperature (SST) anomalies, local land surface conditions, strength of the tropical convergence zones, moisture transport, and large scale circulations. Previous modeling studies by Mechoso et al. (1990) and Giannini et al. (2001) demonstrate that SST anomalies in the tropical Atlantic have significant influences on tropical South America rainfall through trade wind induced moisture convergence anomalies. Marengo (1992), Hastenrath and Greischar (1993), and Uvo et al. (1998) further find that the gradient of SST anomalies across tropical Atlantic can have significant impacts on precipitation in northeastern Brazil and north-central 
Amazonia. The intertropical convergence zone (ITCZ) can be modulated by SST anomalies in the tropical Atlantic, and in turn impact rainfall over northeastern Brazil (Nogués-Paegle and Mo 2002). Precipitation variability over the southeastern South America has also been related to SST anomalies in the adjacent Atlantic Ocean (Díaz et al. 1998; Doyle and Barros 2002; Chaves and Nobre 2004). ENSO-induced large-scale circulation changes through wave dynamics can also modulate precipitation in the tropical and sub-tropical South America (e.g. Aceituno 1988; Kousky and Kayano 1994; Grimm et al. 1998; Grimm et al. 2000). Based on general circulation model (GCM) experiments, Kalnay et al. (1986) suggest that the variability of SACZ is closely linked to the variability of tropical convection in the western Pacific as well as the South Pacific Convergence Zone (SPCZ) through Rossby wave activity propagating from the South Pacific. In regard to the land surface conditions, Grimm et al. (2007) argue that peak precipitation in eastern Brazil is negatively correlated with soil moisture in the antecedent spring season.

Of high relevance to our study, Robertson and Mechoso (2000) using the National Centers for Environmental Prediction/National Center for Atmospheric Research (NCEP/NCAR) Reanalysis dataset (Kalnay et al. 1996) link the variability of SACZ precipitation with the leading mode of variability in large-scale flows over South America. This mode is represented by an equivalent barotropic stationary vortex centered over the Atlantic coast, and is accompanied by a dipole in anomalous vertical motion. An anomalous cyclonic (anti-cyclonic) vortex is associated with intensified (weakened) SACZ, with anomalous descent (ascent) to the southwest. At upper levels, the tendency for the vortex to be advected downstream by the westerly jet is balanced by meridional 
advection of planetary vorticity and stretching associated with vertical motion. At lowlevels, the cyclonic circulation advects warm and moist air from central Amazonia all the way to the southern part of SACZ (near $30^{\circ} \mathrm{W}, 30^{\circ} \mathrm{S}$ ), which maintains the ascending motion.

A suite of recent studies by Lintner and Neelin $(2007 ; 2008 ; 2010)$ examine the processes that control the variability of the margin of tropical convection zones using a combination of theory and observational datasets. These studies suggest that by the influence of low-level inflow winds, certain regional precipitation anomalies are due to shifts in the position of a convective margin, (i.e., a boundary separating convecting and non-convecting regions) the behavior of which is sensitive to inflow from neighboring non-convective regions. The effect of inflow from non-convective region into a continental convection zone is also referred to as "ventilation" of the convective margin (Chou and Neelin 2001). An analytic prototype for convective margin shifts is developed to illustrate the dynamic and thermodynamic factors, i.e., low-level inflow wind speed, top-of-the atmosphere radiative heating, moisture of the inflow air mass, and a moisture threshold condition at which deep convection occurs that set where the convective margin occurs (Lintner and Neelin 2007). Lintner and Neelin (2010) further examine the relationship between low-level inflow and precipitation variability along the margins of tropical convection zones in the tropical South America/Atlantic sector in austral summer using NCEP/NCAR Reanalysis (Kalnay et al., 1996) and Climate Prediction Center (CPC) Merged Analysis of Precipitation (CMAP; Xie and Arkin 1997) datasets. The results indicate that convection along the eastern margin of the SACZ can be suppressed due to modification of the moisture field by inflow air with low moist static energy 
(MSE) from the Atlantic Ocean because the level of moisture becomes subcritical for convection. Modification of the air mass by low level convergence and diabatic effects eventually reaches the threshold for the onset of convection, but for stronger inflow wind, this tends to occur further downstream. Such inflow-related precipitation variations may account for up to $80 \%-90 \%$ of the precipitation variability in sectors of eastern South American convective margin. Robertson and Mechoso (2000), and Lintner and Neelin (2010), therefore, both point to low-level wind anomalies as crucial to the moisture advection in the production of important modifications in convection along the convective margins of the South American region.

The present study will focus on the ability of climate models to represent the sensitivity of precipitation to the low-level anomalous flows and the associated moisture advection over the convective margin in eastern Brazil and eastern edge of the SACZ on interannual time scales. For brevity, we will refer to this region as the eastern Brazil/SACZ convective margin. The climate model we used in this study is the University of California Los Angeles (UCLA) atmospheric GCM (AGCM). Our approach is based on the analysis of AGCM simulations and observational datasets. The hypothesis is that low-level inflow variability in association with the leading mode of interannual variability identified by Robertson and Mechoso (2000) is responsible for the precipitation variability over the eastern Brazil/SACZ convective margin according to the mechanism proposed by Lintner and Neelin $(2007,2010)$. We also analyze three AGCM mechanism-testing simulations specially designed to examine our hypothesis.

The remainder of the text is organized into five sections. Section 2 provides a brief introduction to the observational datasets and the UCLA AGCM. Section 3 
demonstrates the sensitivity of SACZ variability to the low-level inflows from observational datasets and AGCM simulations. Section 4 examines the AGCM mechanism-testing simulations. Section 5 presents a summary and our conclusions.

\section{Datasets, model and methodology}

\section{a. Observational datasets}

We use the global dataset from the NCEP/NCAR Reanalysis (Kalnay et al. 1996), which covers the period from 1948 to the present date. We also use monthly-mean global precipitation fields from CMAP (Xie and Arkin 1997). CMAP, which merges observations from raingauges and estimates from several satellite-based algorithms (infrared and microwave) covers the period 1979-2006. We interpolate the fields in both datasets into a $2.5^{\circ}$ longitude by $2.0^{\circ}$ latitude grid to match the horizontal resolution of the AGCM.

\section{b. Atmospheric model: UCLA AGCM}

The UCLA AGCM includes advanced parameterizations of the major physical processes in the atmosphere. The parameterization of cumulus convection, including its interaction with the planetary boundary layer $(\mathrm{PBL})$, follows the prognostic version of Arakawa and Schubert (1974) (Pan and Randall 1998). The parameterization of radiative processes is based on Harshvardhan et al. (1987; 1989), and the parameterization of PBL processes is based on the mixed-layer approach of Suarez et al. (1983), as revised by Li et al. (2002). Surface heat fluxes are calculated following the bulk formula proposed by Deardorff (1972) and modified by Suarez et al. (1983). The model also includes the parameterizations of prognostic cloud liquid water and ice (Köhler 1999), and the effects 
of cumulus clouds on the radiation calculations. A more detailed description of the model can be found in Arakawa (2000) and Mechoso et al. (2000), or online at http://www.atmos.ucla.edu/ mechoso/esm/agcm.html. The most recent versions of the AGCM are coupled to the first-generation Simplified Simple Biosphere model (SSiB, Xue et al. 1991). In this model, several sources of data (Dorman and Sellers, 1989; Xue et al., 1996a, 1996b) were used to determine the vegetation types that specify monthly climatological land surface properties (e.g. leaf area index, green leaf fraction and surface roughness length).

In the present study, we use AGCM version 7.1 with a horizontal resolution of $2.5^{\circ}$ latitude and $2^{\circ}$ longitude, and 29 layers in the vertical. The distributions of green house gases, sea ice, and ocean surface albedo are all prescribed corresponding to a monthly observed climatology. The prescribed SST fields are taken from NOAA Extended Reconstructed monthly SST V2 (Smith and Reynolds 2004). SSiB has three soil layers and one vegetation layer. More model details, and the highly realistic AGCM performance on South American warm season climate, are reported in Ma et al. (2010). The AGCM simulation analyzed in this study covers the period from January 1948 to February 2005.

\section{c. Methodology}

Figure 1 displays the monthly mean precipitation and its variance for December, January, and February from both CMAP and AGCM simulation. The patterns of monthly mean precipitation or variance are very similar in the three summer months. The distributions from CMAP show strong convection in central Amazonia, the Atlantic ITCZ, and the SACZ. Large precipitation variance is found over the western to central 
Atlantic ITCZ, and the eastern sector of the SACZ between $60^{\circ}-30^{\circ} \mathrm{W}$ and $10^{\circ}-20^{\circ} \mathrm{S}$. In the simulation, the Atlantic ITCZ is weaker, and the precipitation variance shows large values only over the eastern Brazil/SACZ convective margin, with smaller amplitude than in CMAP. The smaller amplitude of the precipitation variance in the simulation is mainly due to the limitation of conventional GCMs in reproducing all scales of convective systems (e.g. Xiao and Mechoso 2009). According to Lintner and Neelin (2010), as reviewed in the Introduction, the precipitation variability over the eastern Brazil/SACZ convective margin reflects shifts in the position of the convective margin (i.e., the boundary separating convecting and non-convecting regions), the behavior of which is sensitive to land region moisture inflow from a neighboring ocean region. Figure 1 confirms that the precipitation boundary is collocated with the large precipitation variance over the eastern Brazil/SACZ convective margin in both observations and simulation. Since monthly mean precipitation shows similar patterns in the three summer months, we will concentrate on February for detailed analysis of precipitation variability along a mean low-level inflow trajectory from both observational datasets and model simulations.

We start by constructing a wind index for the investigation of the inflow-related precipitation variability. First, we identify the region of large precipitation variability. The region marked by the box in Fig. $1\left(55^{\circ} \mathrm{W}-40^{\circ} \mathrm{W}, 20^{\circ} \mathrm{S}-10^{\circ} \mathrm{S}\right)$ lies in the eastern Brazil/SACZ convective margin where large precipitation variability is found in both the observation and simulation. In this region, the direction of mean $850 \mathrm{hPa}$ zonal flows is approximately perpendicular to precipitation contours (i.e. along the precipitation gradient). The wind index is defined as the $850 \mathrm{hPa}$ zonal mean wind averaged over the 
box marked in Fig. 1 and normalized by the standard deviation of its time series for the entire period of study. Figure 2 shows the time series of wind indices for both the observation and simulation. We define "positive phase" and "negative phase" of the wind index to the periods in which this is either greater or smaller than one or minus one, respectively. Note that the wind index for the observation (NCEP/NCAR Reanalysis) is plotted from 1979 to 2005 only, which corresponds to the period covered by CMAP.

We identify three positive and five negative phases from the observations, and six positive and seven negative phases from simulations. In the following we concentrate on the composite plots for those two phases.

\section{Precipitation variability in the eastern Brazil/SACZ convective margin}

Figures $3 \mathrm{a}$ and $3 \mathrm{~b}$ show composites of precipitation from CMAP, and of $850 \mathrm{hPa}$ wind anomalies from the NCEP/NCAR Reanalysis during the two phases. The shading indicates values that are statistically significant at the $95 \%$ confidence level according to a Student's t-test (Wilks 2006). Anomalies are defined in reference to the overall February mean. During the positive phase, precipitation anomalies are positive over central Brazil and SACZ, and $850 \mathrm{hPa}$ wind anomalies show a northwest-southeast elongated cyclonic circulation centered around $\left(35^{\circ} \mathrm{W}, 30^{\circ} \mathrm{S}\right)$. During the negative phase, precipitation anomalies are negative over eastern Brazil, and $850 \mathrm{hPa}$ wind anomalies show a northwest-southeast elongated anti-cyclonic circulation centered around $\left(35^{\circ} \mathrm{W}\right.$, $30^{\circ} \mathrm{S}$ ). The precipitation anomalies in both phases are nearly collocated with the large precipitation variance of the SACZ (Fig. 1). The anomalous circulation is equivalent 
barotropic, and this vortex resembles the leading mode of variability on interannual time scales over South America during austral summer identified by Robertson and Mechoso (2000).

Figure 4 shows composites of precipitation and $850 \mathrm{hPa}$ wind anomalies from the simulation during the two phases. Precipitation anomalies form a dipole pattern with one pole over the eastern Brazil/SACZ convective margin and another over the La Plata Basin. The wind anomalies show a more distinct vortex. There is an overall consistency between anomalous precipitation and winds in the observation and simulation. The precipitation anomalies over the SACZ in both cases show large values over the eastern Brazil/SACZ convective margin. The difference between maximum precipitation in the two phases can be as large as $8 \mathrm{~mm} \mathrm{day}^{-1}$ in magnitude.

The general tendency of stronger (weaker) precipitation over the eastern Brazil/SACZ convective margin to occur with weaker (stronger) inflow in reference to mean easterly trades can be interpreted in the context of the convective margins prototype (Lintner and Neelin 2007). Figure 5 shows composites of MSE in the PBL (lowest AGCM level) and anomalous winds at $850 \mathrm{hPa}$ from the simulations during the two phases. The MSE $\square$ is defined as:

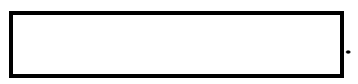

where $c_{p}$ is specific heat capacity of dry air at constant pressure, $T$ is temperature, $g$ is gravity, $\mathrm{z}$ is geopotential height, $L$ is latent heat of vaporization, and $q$ is specific humidity. The units of MSE in Figures 5, 7, and 9 have been converted into K by multiplying $c_{p}^{-1}$. The MSE patterns are similar during both phases, and show large values in the western portion of the Amazon basin. The MSE values decrease eastward gradually 
on the Brazilian Highland, and then decrease significantly away from the coast of South America. Figure 6 further shows composites of simulated advection of MSE by the anomalous flows $\left(-\mathbf{v}^{\prime} \cdot \nabla h_{m}\right)$ in the PBL. Anomalous winds at $850 \mathrm{hPa}$ during the positive phase over the eastern Brazil show strong westerly anomalies that are approximately across the MSE contours (i.e. along the local MSE gradient). This suggests that weakening of the easterly trades facilitates the development of higher MSE values over eastern Brazil/SACZ convective margin. During the negative phases, on the contrary, anomalous winds at $850 \mathrm{hPa}$ over eastern Brazil show strong easterlies nearly along the MSE gradient, which indicates a strong downstream flux of low MSE from the Atlantic Ocean to eastern Brazil. These features are consistent with the positive (negative) advection of MSE by the anomalous flows over eastern Brazil during the positive (negative) phase in Figure 6. Higher MSE favors stronger convection, and is consistent with increased precipitation at the SACZ. Inflow of air with lower MSE suppresses convection until other effects such as evaporation or radiatively-driven convergence increase the air moisture above the convective threshold (Lintner and Neelin 2010). We can also see in Fig. 5 the shifts in convective margin (the boundary between shaded and non-shaded areas) over the eastern Brazil/SACZ due to the anomalous advection of MSE. The physical interpretation of the choice of $4 \mathrm{~mm} \mathrm{day}^{-1}$ as a proxy for identification of convective margin can be referred to Chou et al. (2009) or Lintner and Neelin (2010).

This analysis suggests that anomalous precipitation in the eastern Brazil/SACZ convective margin is associated with anomalous advection of MSE at lower levels in the troposphere. Since MSE patterns in the PBL are similar in both phases of our wind index, 
we conjecture that the main mechanism for interannual variability of precipitation along the eastern Brazil/SACZ convective margin is ventilation by circulation anomalies associated with the leading mode of circulation variability over South America in summertime. To support this, we aim to show that the wind anomalies have a causal impact on the precipitation, via the advection of low MSE air into the convective margin.

\section{AGCM mechanism-testing experiments}

\section{a. Experimental design}

To challenge our conjecture on the role played by low-level wind variability and the leading mode of interannual variability on the generation of precipitation anomalies over the eastern Brazil/SACZ convective margin, we perform and analyze three AGCM mechanism-testing experiments. These experiments aim to demonstrate that in a quasisteady (i.e. with no seasonal cycle) climate state a time-independent perturbation similar to the wind anomalies from the simulation during the two phases of the $850 \mathrm{hPa}$ wind index - and confined to the region where those anomalies have substantial amplitudes will result in a quasi-steady displacement of the eastern Brazil/SACZ convective margin. The quasi-steady climate state is obtained by integrating the AGCM in perpetualFebruary mode. This strategy also by-passes the need for multi-year integrations otherwise needed to have statistically significant results for the southern summer season. In the perpetual-February mode, the solar declination angle and all boundary conditions including SST, ground properties and albedo at the ocean surface are prescribed in the AGCM to be those corresponding to February 15 and remain unchanged through the entire model integration. The steady perturbation to the velocity field is required to be 
non-divergent in order not to generate vertical velocity that would directly lead to precipitation. In addition, the artificial perturbation is restricted to the low levels of the troposphere where moisture transports are important and to the region overlapping the eastern to southern Brazil and western Atlantic Ocean $\left(90^{\circ} \mathrm{W}-10^{\circ} \mathrm{W}, 50^{\circ} \mathrm{S}-10^{\circ} \mathrm{N}\right)$. To produce an artificial perturbation with those characteristics, we start by selecting the horizontal wind anomalies $(\square$ ) at the lowest four AGCM levels for both the positive and negative phases of the wind index from the simulation analyzed in section 3 . Next, we separate the wind anomalies into their divergent and rotational (non-divergent) components: where $\square$ is velocity potential and $\square$ is streamfunction. The second component does not contribute to the divergence field. For technical reasons, this separation is done in sigma coordinate. Thus in regions of topographic slope, there will have some imposed vertical motion which can directly impact precipitation processes. For most of the region of interest this is not an issue, but some effect at the edge of the Andes can occur and should be ignored in interpretation of the results. We perform three mechanism-testing experiments. The first is a twelve-month long integration that will provide our reference, and will be referred to as CONTROL. We then conduct a pair of imposed-wind experiments, in which we artificially impose wind perturbations corresponding to the positive and negative phases, respectively, obtained according to the method described above, with the wind perturbations acting only in the moisture advection in the model equations. We only change the moisture advection since it is the dominant term in the MSE advection.

Figure 7 shows the wind perturbations in the PBL used in the imposed-wind experiments for both the positive and negative phases, as well as the composites of MSE 
from Fig. 5. A comparison with Figure 5 illustrates the similarity with the wind fields except for smaller magnitudes in some regions (due to being only the purely rotational component). The imposed-wind experiments are also twelve months long and will be referred to as POSEXP and NEGEXP for the positive phase and negative phase experiment, respectively.

\section{b. Experiment Results}

Figure 8 presents the mean precipitation for the imposed-wind experiments, as well as the difference between POSEXP and NEGEXP. The experiments capture the overall precipitation features of South American warm season climate relatively well: there is strong convection in central Amazonia and the SACZ. The largest differences are over the eastern Brazil/SACZ convective margin. POSEXP shows a precipitation maximum (Fig. 8b), while NEGEXP shows weaker precipitation (Fig. 8c). The impact of the imposed wind anomalies on precipitation is clear in Figure 8: along the convective margins, weakened inflow in reference to the easterly trades from the Atlantic Ocean leads to strengthened precipitation, and strengthened inflow leads to lower precipitation. The difference between POSEXP and NEGEXP can be locally as large as $4 \mathrm{~mm}^{-1}{ }^{-1}$ (Fig. 8d). The precipitation difference here is smaller comparing to the difference shown in Fig. $4\left(8 \mathrm{~mm} \mathrm{day}^{-1}\right)$. This is due to several reasons, and the experiment design which excludes the effects of temperature advection (part of the MSE advection) and moisture convergence is the main reason for such difference. Nevertheless, the results suggest that moisture advection is the main contributor to the precipitation difference over the convective margin between the two phases. Figure $8 \mathrm{~d}$ also shows negative values of large magnitude with center over the Andes Mountains around $\left(70^{\circ} \mathrm{W}, 12^{\circ} \mathrm{S}\right)$. These features 
are influenced by differences in orography-induced precipitation, which should be regarded as discussed above.

Figure 9 presents the differences between POSEXP and NEGEXP with CONTROL, as well as the mean MSE averaged over the lowest four AGCM levels in both phases. In POSEXP, the MSE has a maximum in central Brazil, and decreases eastward over the Brazilian Highland and off the Atlantic coast of South America. With the imposed-wind perturbations, westerly anomalies are apparent over the eastern Brazil/SACZ convective margin, which suggests weaker easterly trades and reduced low MSE flux from Atlantic Ocean to Eastern Brazil. In NEGEXP, the pattern of MSE is similar except that the maximum is in western Brazil. The wind anomalies, on the other hand, increase the advection of low MSE air from the Atlantic Ocean to eastern Brazil. These results further suggest that in addition to the imposed-wind perturbations that contributes to the moisture advection, the velocity field responses in the experiments also provides additional moisture flux which positively feedbacks in precipitation fields over the eastern Brazil/SACZ convective margin.

\section{Summary and conclusions}

It is demonstrated that the eastern Brazil/SACZ convective margin in the austral summer is sensitive to the variability of low-level flows on interannual time scales. In addition to showing an association of low-level inflow and precipitation change in observational datasets and AGCM simulations, AGCM mechanism-testing experiments demonstrate a causal connection via moisture advection.

Defining a low-level wind index in a region $\left(850 \mathrm{hPa}, 55^{\circ} \mathrm{W}-40^{\circ} \mathrm{W}, 20^{\circ} \mathrm{S}-10^{\circ} \mathrm{S}\right)$ where both observed and simulated precipitation variances are large, precipitation in the 
selected region shows positive (negative) anomalies during positive (negative) phases of the wind index over the eastern Brazil/SACZ convective margin. Figure10 provides a schematic diagram illustrating the underlying mechanism. During positive phases, positive precipitation anomalies are consistent with stronger convection which is associated with weakening of the easterly trades. The weaker trades that reduce the advection of low MSE air from the Atlantic Ocean promote convection over the eastern Brazil/SACZ convective margin. During negative phases, negative precipitation anomalies are consistent with weaker convection which is associated with stronger easterly trades that increase the advection of low MSE air from the Atlantic Ocean. Inflow air with lower MSE suppresses convection until other effects increase the moisture of air above the convective threshold. The anomalous inflows which affect the intensity of mean easterly trades are associated with the leading mode of wind variability over sub-tropical South America (Robertson and Mechoso 2000). These results are consistent with the theoretical work proposed on convective margins by Linter and Neelin $(2007,2010)$, and ventilation mechanism by Chou and Neelin (2001).

AGCM imposed-wind experiments to test the causal role of horizontal moisture advection by low-level inflow wind in creating precipitation anomalies over the convective margin are designed as follows. A steady perturbation of the horizontal velocity field is artificially imposed in the moisture equation that resembles the spatial pattern of observed wind anomalies (but nondivergent in order not to generate vertical velocities). The precipitation difference between positive and negative phase experiments can be as large as $4 \mathrm{~mm}$ day $^{-1}$. Since the MSE fields during both phases are almost identical to each other, the differences in precipitation can be attributed to the difference 
in low-level flows. In addition to the imposed-wind perturbations that contribute to the moisture advection, there is also a velocity field response in these experiments, which tends to reinforce the initial effect with additional moisture advection. This thus represents a positive feedback on precipitation anomalies over the eastern Brazil/SACZ convective margin.

Our analysis supports the conjecture that the connection between precipitation variability over the eastern Brazil/SACZ convective margin, and the leading mode of variability over the sub-tropical South America (Robertson and Mechoso 2000) is established substantially via the ventilation mechanism for the variability of convective margins (Lintner and Neelin 2007; 2010). The ability of the AGCM to capture the sensitivity of SACZ precipitation to the low-level inflow variability raises the question of potential predictability. In austral summer, the leading mode of variability over South America has no strong correlation with ENSO related SST anomalies or with the PacificSouth America mode in the south Pacific (Zamboni et al. 2010). While Robertson and Mechoso (2000) note some correlation of the vortex with southwest Atlantic SST anomalies, we have not found clear association with SST and the inflow winds here. We thus assume that the variability is largely atmospheric internal variability. Nevertheless, the mechanism tested here, in which changes in the ventilation of the convective margin impact the precipitation would apply on any time scale, given a perturbation to the inflow. The imposed-wind experiments provide a clear method for testing the impact of anomalous ventilation on precipitation over convective margins that can be applied to other regions. 


\section{Acknowledgments.}

We thank Dr. Benjamin Lintner for very helpful comments and Joyce Meyerson for graphical assistance. Computing resources were provided from the NCAR computational and information systems laboratory. This research was supported by NOAA under grants NA08OAR4310597 and NA08OAR4310882 and by NSF under grant ATM-0645200.

This work performed under the auspices of the U.S. Department of Energy by Lawrence Livermore National Laboratory under Contract DE-AC52-07NA27344. 


\section{References}

Aceituno, P., 1988: On the functioning of the Southern Oscillation in the South American sector. Mon. Wea. Rev., 116, 505-525.

Arakawa, A., 2000: A personal perspective of the early years of general circulation modeling at UCLA. General Circulation Model Development: Past, Present, and Future. Proceedings of a Symposium in Honor of Professor Akio Arakawa, D. A. Randall, Ed., Academic Press, 1-65.

Arakawa, A., and W. H. Schubert, 1974: Interaction of a cumulus ensemble with the large-scale environment. Part I. J. Atmos. Sci., 31, 674-701.

Chaves, R. R., and P. Nobre, 2004: Interactions between the South Atlantic Ocean and the atmospheric circulation over South America. Geophys. Res. Lett., 31, L03204, doi:10.1029/2003GL018647.

Chou, C. and J. D. Neelin, 2001: Mechanisms limiting the southward extent of the South American summer monsoon. Geophys. Res. Lett., 28, 2433-2436.

Chou, C., C.-A. Chen, and J.-Y. Tu, 2009: Evaluating the "rich-get-richer" mechanism in tropical precipitation change under global warming. J. Climate, 22, 1982-2005.

Deardorff J. W., 1972: Parameterization of the planetary boundary layer for use in general circulation models. Mon. Wea. Rev., 100, 93-106.

Díaz, A. F., C. D. Studzinski, and C. R. Mechoso, 1998: Relationships between precipitation anomalies in Uruguay and southern Brazil and sea surface temperature in the Pacific and Atlantic Oceans. J. Climate, 11, 251-271. 
Dorman J. L., and P. Sellers, 1989: A global climatology of albedo, roughness length and stomatal resistance for atmospheric general circulation models as represented by the Simple Biosphere Model (SiB). J. Appl. Meteor, 28, 833-855.

Doyle, M. E., and V. R. Barros, 2002: Midsummer low-level circulation and precipitation in subtropical South America and related sea surface temperature anomalies in the South Atlantic. J. Climate, 15, 3394-3410.

Giannini, A., J. C. H. Chiang, M. Cane, Y. Kushnir, and R. Seager, 2001: The ENSO teleconnection to the tropical Atlantic Ocean: Contributions of the remote and local SSTs to rainfall variability in the tropical Americas. J. Climate, 14, 4530-4544.

Grimm, A. M., V. R. Barros, and M. E. Doyle, 2000: Climate variability in southern South America associated with El Niño and La Niña events. J. Climate, 13, 35-58.

Grimm, A. M., S. Ferraz, and J. Gomez, 1998: Precipitation anomalies in southern Brazil associated with El Niño and La Niña events. J. Climate, 11, 2863-2880.

Grimm, A.M., J.S. Pal, and F. Giorgi, 2007: Connection between Spring Conditions and Peak Summer Monsoon Rainfall in South America: Role of Soil Moisture, Surface Temperature, and Topography in Eastern Brazil. J. Climate, 20, 5929-5945. Harshvardhan, R. Davies, D. A. Randall, and T. G. Corsetti, 1987: A fast radiation parameterization for atmospheric circulation models. J. Geophys. Res., 92, 1009-1016. Harshvardhan, R. Davies, D. A. Randall, T. G. Corsetti, and D. A. Dazlich, 1989: Earth radiation budget and cloudiness simulations with a general circulation model. J. Atmos. Sci., 46, 1922-1942.

Hastenrath, S. and L. Greischar, 1993: Further work on the prediction of northeast Brazil rainfall anomalies. J. Climate, 6, 743-758. 
Kalnay, E., M. Kanamitsu, R. Kistler, W. Collins, D. Deaven, L. Gandin, M. Iredell, S. Saha, G. White, J. Woollen, Y. Zhu, A. Leetmaa, B. Reynolds, M. Chelliah, W. Ebisuzaki, W. Higgins, J. Janowiak, K.C. Mo, C. Ropelewski, J. Wang, R. Jenne and D. Joseph, 1996: The NECP/NCAR 40-Year Reanalysis Project. Bull. Amer. Meteor. Soc., 77, 437-471.

Kalnay E., K. C. Mo and J. Paegle, 1986: Large-Amplitude, short-scale stationary Rossby waves in the southern hemisphere: Observations and mechanistic experiments to determine their origin. J. Atmos. Sci., 43, 252-275.

Köhler, M., 1999: Explicit prediction of ice clouds in general circulation models. Ph.D. Dissertation, Department of Atmospheric Sciences, University of California, Los Angeles, 167 pp.

Kousky, V. E. and M. Y. Kayano, 1994: Principal modes of outgoing longwave radiation and 250-mb circulation for the South American sector. J. Climate , 7, 1131-1143.

Li, J. -L., M. Köhler, J. D. Farrara and C. R. Mechoso, 2002: The impact of stratocumulus cloud radiative properties on surface heat fluxes simulated with a general circulation model. Mon. Wea. Rev., 130, 1433-1441.

Lintner, B. R. and J. D. Neelin, 2007: A prototype for convective margin shifts. Geophys. Res. Lett., 34, L05812, doi:10.1029/2006GL027305.

Lintner, B. R. and J. D. Neelin, 2008: Eastern margin variability of the South Pacific Convergence Zone. Geophys. Res. Lett., 35, L16701, doi:10.1029/2008GL034298.

Lintner, B. R. and J. D. Neelin, 2010: Tropical South America/Atlantic sector convective margins and their relationship to low-level inflow. J. Clim., 23, 2671-2685, doi: 10.1175/2009JCLI3301.1. 
Ma, H.-Y., C. R. Mechoso, Y. Xue, H. Xiao, C.-M. Wu, J.-L. Li, and F. De Sales, 2010: Impact of land surface processes on the South American warm season climate. Clim. Dyn. doi: 10.1007/s00382-010-0813-3.

Marengo, J. A., 1992: Interannual variability of surface climate in the Amazon basin. Int. J. Climatol., 12, 853-863.

Mechoso, C. R., S. Lyons, and J. Spahr, 1990: The impact of sea surface temperature anomalies on the rainfall in northeast Brazil. J. Climate, 3, 812-826.

Mechoso, C. R., J. -Y. Yu and A. Arakawa, 2000: A coupled GCM pilgrimage: From climate catastrophe to ENSO simulations. General Circulation Model Development: Past, present and future. Proceedings of a Symposium in Honor of Professor Akio Arakawa. D. A. Randall. Ed., Academic Press, 539-575.

Nogués-Paegle, J. and K. Mo, 2002: Linkages between summer rainfall variability over South America and sea surface temperature anomalies. J. Climate, 15, 1389-1407.

Pan, D. -M., and D. A. Randall, 1998: A cumulus parameterization with a prognostic closure. Quart. J. Roy. Meteor. Soc., 124, 949-981.

Robertson, A. W. and C. R. Mechoso, 2000: Interannual and interdecadal variability of the South Atlantic convergence zone. Mon. Wea. Rev., 128, 2947-2957.

Smith, T. M. and Reynolds R. W., 2004: Improved extended reconstruction of SST (1854-1997). J. Climate. 17, 2466-2477.

Suarez, M. J., A. Arakawa and D. A. Randall, 1983: The parameterization of the planetary boundary layer in the UCLA general circulation model: formulation and results. Mon. Wea. Rev., 111, 2224-2243. 
Uvo, C. R. B., C. A. Repelli, S. Zebiak, and Y. Kushnir, 1998: The relationship between tropical Pacific and Atlantic SST and northeast Brazil monthly precipitation. J. Climate, 11, 551-562.

Vera C., et al. 2006: Toward a unified view of the American Monsoon Systems. $J$. Climate, 19, 4977-5000.

Wilks, D. S., 2006: Statistical Methods in the Atmospheric Sciences. 2nd ed. International Geophysical Series, Vol. 91, Academic Press, 627 pp.

Xiao, H. and C. R. Mechoso, 2009: Seasonal cycle-El Niño relationship: Validation of hypotheses. J. Atmos. Sci., 66, 1633-1653.

Xie, P., and P.A. Arkin, 1997: Global precipitation: A 17-year monthly analysis based on gauge observations, satellite estimates, and numerical model outputs. Bull. Amer. Meteor. Soc., 78, 2539-2558.

Xue, Y., P. J. Sellers, J.L. Kinter III, and J. Shukla, 1991: A simplified biosphere model for global climate studies. J. Climate, 4, 345-364.

Xue Y., H. G. Bastable, P. A. Dirmeyer, and P. J. Sellers, 1996a: Sensitivity of simulated surface fluxes to changes in land surface parameterization-A study using ABRACOS data. J. Appl. Meteor, 35, 386-400.

Xue, Y., M. J. Fennessy, and P. J. Sellers, 1996b: Impact of vegetation properties on U.S. summer weather prediction, J. Geophys. Res., 101(D3), 7419-7430.

Zamboni, L., C. R. Mechoso, and F. Kucharski. 2010: Relationships between upper-level circulation over South America and rainfall over southeastern South America: A physical base for seasonal predictions. J. Climate, 23, 3300-3315. 


\section{List of Figures}

FIG. 1. Mean precipitation (mm day ${ }^{-1}$, shaded) and its variance $\left(\mathrm{mm}^{2} \mathrm{day}^{-2}\right.$, contour) for December, January, and February from CMAP, and the simulation. The contour interval is $2 \mathrm{~mm}^{2} \mathrm{day}^{-2}$. The boxes $\left(55^{\circ} \mathrm{W}-40^{\circ} \mathrm{W}, 20^{\circ} \mathrm{S}-10^{\circ} \mathrm{S}\right)$ in the plots for February mark the regions selected for calculation of $850 \mathrm{hPa}$ wind indices.

FIG. 2. Time series of February $850 \mathrm{hPa}$ wind index from NCEP/NCAR reanalysis (black curve) and AGCM (grey curve). See text for the definition of wind index, and Fig. 1 for averaging region.

FIG. 3. Composites of February anomalies in precipitation ( $\mathrm{mm} \mathrm{day}^{-1}$, contours) and 850 $\mathrm{hPa}$ wind $\left(\mathrm{m} \mathrm{s}^{-1}\right.$, arrows) from CMAP and NCEP/NCAR Reanalysis, during the (a) positive and (b) negative phases based on the $850 \mathrm{hPa}$ wind index. The shaded regions correspond to values of precipitation anomalies that are significant at the $95 \%$ confidence level. The contour interval is $1 \mathrm{~mm} \mathrm{day}^{-1}$.

FIG. 4. Same as Fig. 3, except for the simulation.

FIG. 5. Composites of simulated February mean moist static energy (K, contours) in the PBL and $850 \mathrm{hPa}$ wind anomalies ( $\mathrm{m} \mathrm{s}^{-1}$, arrows) during the (a) positive and (b) negative phases based on the $850 \mathrm{hPa}$ wind index. Also plotted in (a) and (b) are the shaded areas where composites of simulated February mean precipitation are larger than $4 \mathrm{~mm}$ day $^{-1}$. The boundary is used as a proxy for the identification of convective margin.

FIG. 6. Composites of simulated February advection of moist static energy by the anomalous flows $\left(-\mathbf{v}^{\prime} \bullet \nabla h_{m}\right)$ in the PBL during the (a) positive and (b) negative phases based on the $850 \mathrm{hPa}$ wind index. The contour interval is $0.003\left(\mathrm{~m}^{2} \mathrm{~s}^{-3}\right)$. 
FIG. 7. Composites of simulated February mean moist static energy (K, contours) and non-divergent component of anomalous winds ( $\mathrm{m} \mathrm{s}^{-1}$, arrows) in the PBL during the (a) positive and (b) negative phases of the $850 \mathrm{hPa}$ wind index. See text for more information.

FIG. 8. Mean precipitation (mm day ${ }^{-1}$ ) from (a) CONTROL, (b) POSEXP, and (c) NEGEXP. See text for the experiments description. Also plotted in (d) is the difference of precipitation between (b) and (c).

FIG. 9. Mean moist static energy ( $\mathrm{K}$, contours) and wind anomalies ( $\mathrm{m} \mathrm{s}^{-1}$, arrows) averaged over the lowest four AGCM levels from (a) POSEXP and (b) NEGEXP. FIG. 10. Schematic diagram of the mechanism for the precipitation variability of the eastern Brazil/SACZ convective margin during positive/negative phases as defined by the intensity of low-level easterly trades. Color shades represent the MSE and white shades represent regions where deep convection occurs. Variability of the low-level easterly trades which are associated with the leading mode of wind variability on interannual time scales can modify the import of low MSE into the convective margin as represented by the red/blue arrow during positive/negative phases, and convection over the convective margin can be modified substantially through the "ventilation" effect. 


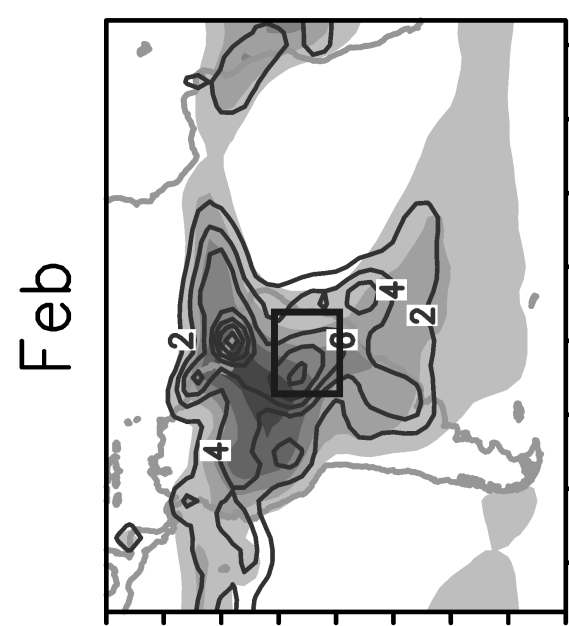

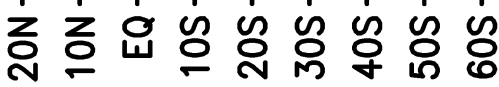

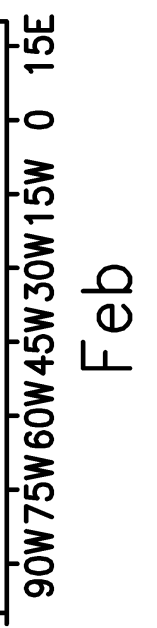

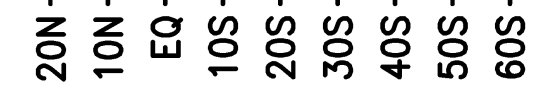

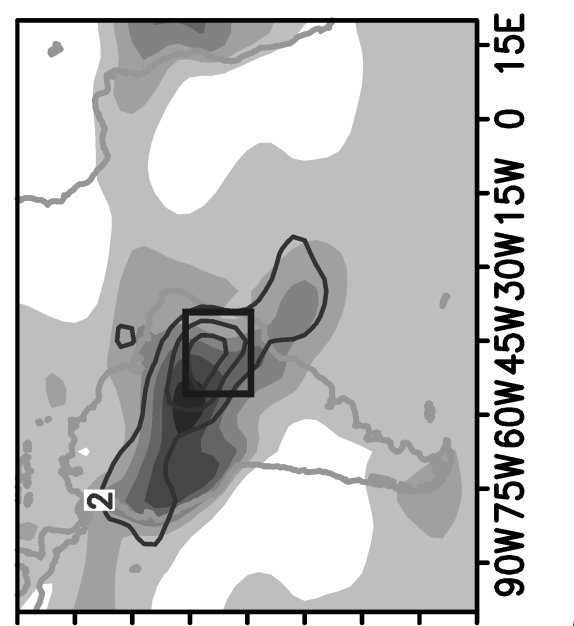

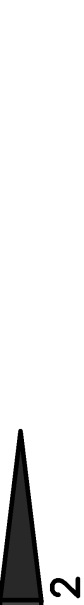

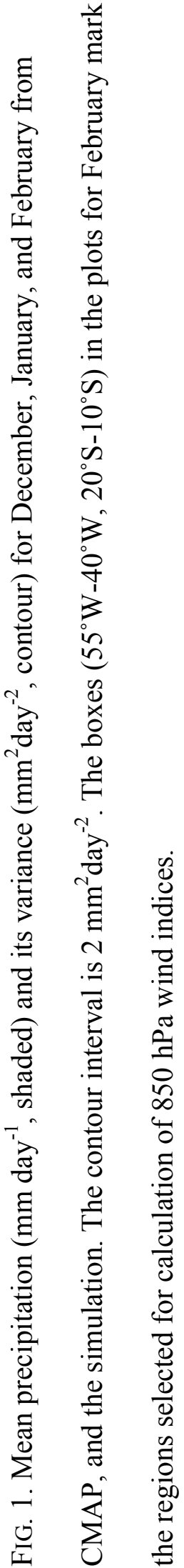

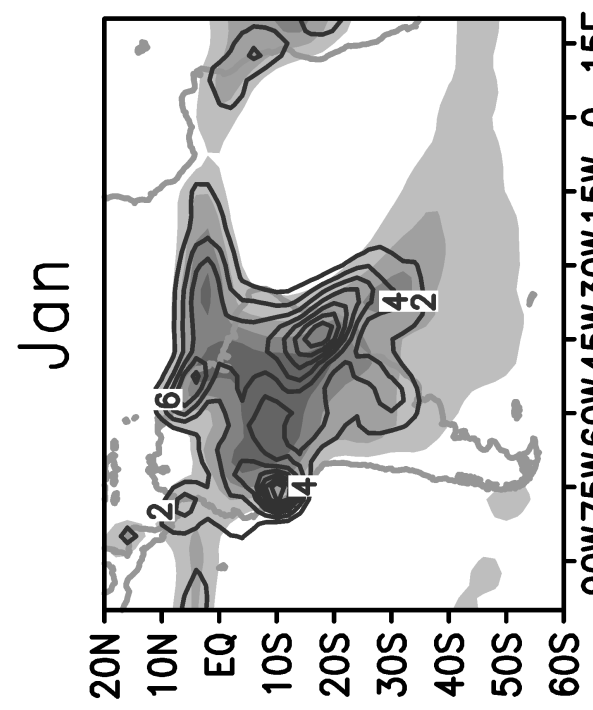
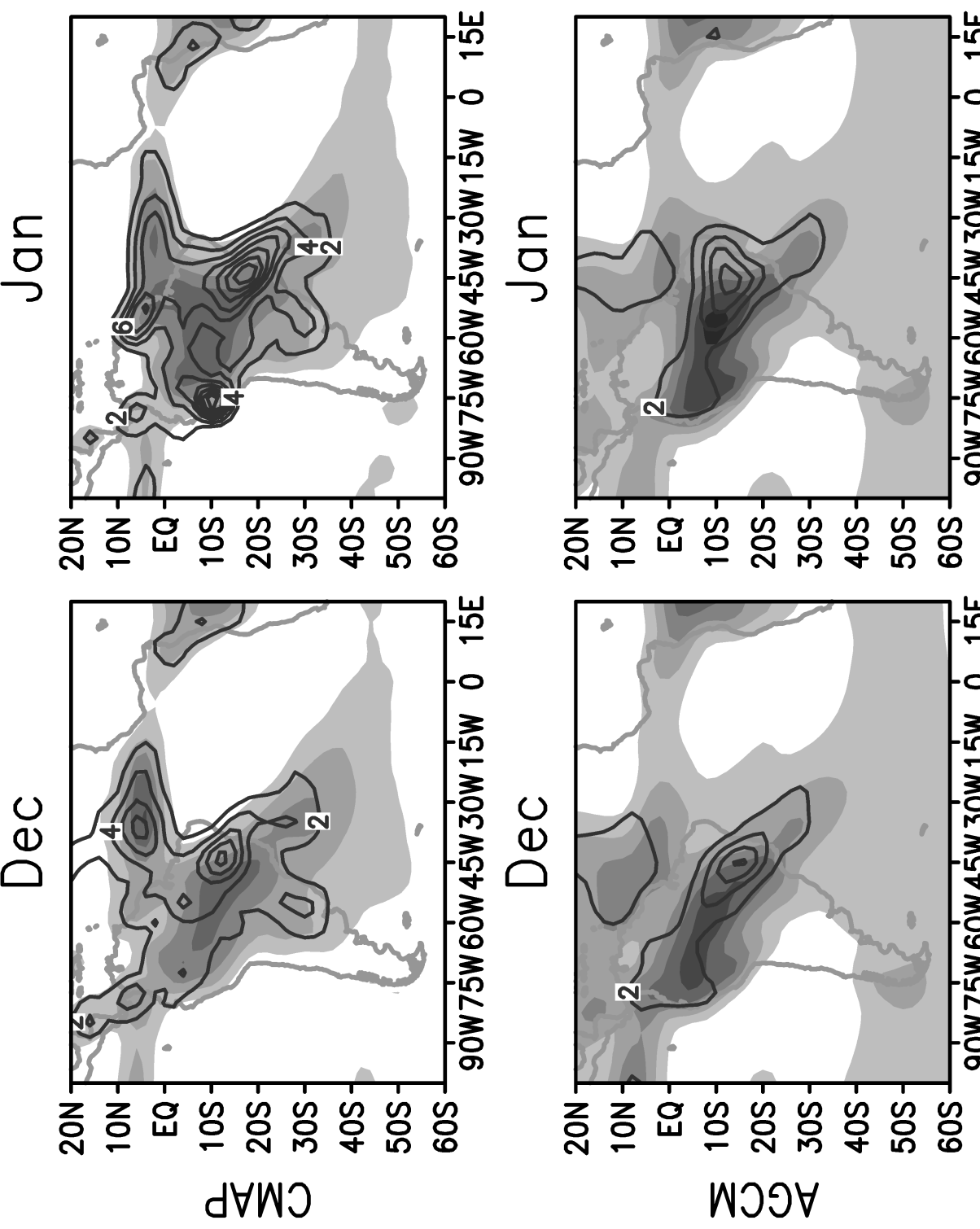

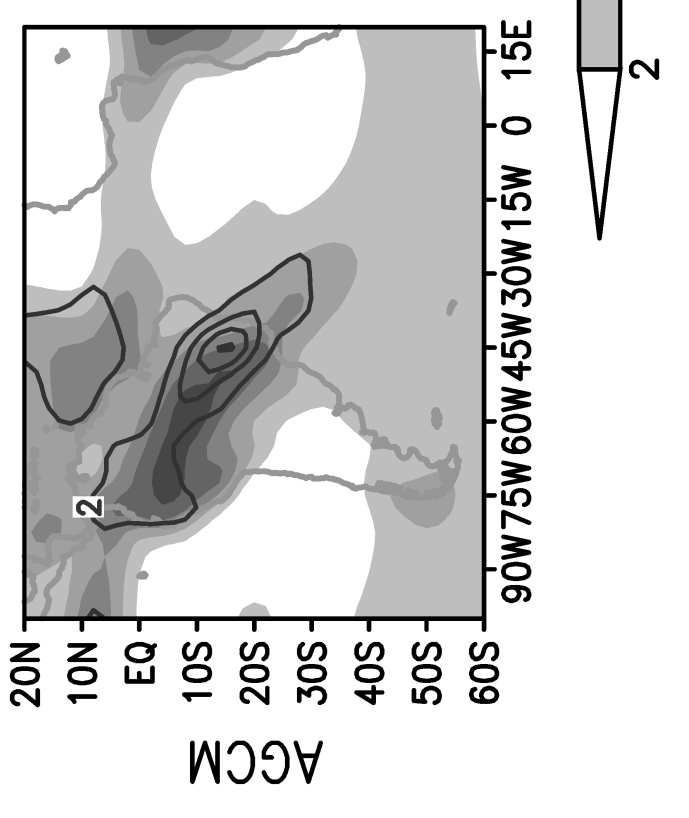

$\dot{0}$
0
0
$\Xi$
0
0
0
0
0
0
0
0
0
0
.0
0
0
0
0
0
0
0
0
0
0
0
0
0
00
0
0
$\Xi$
0 


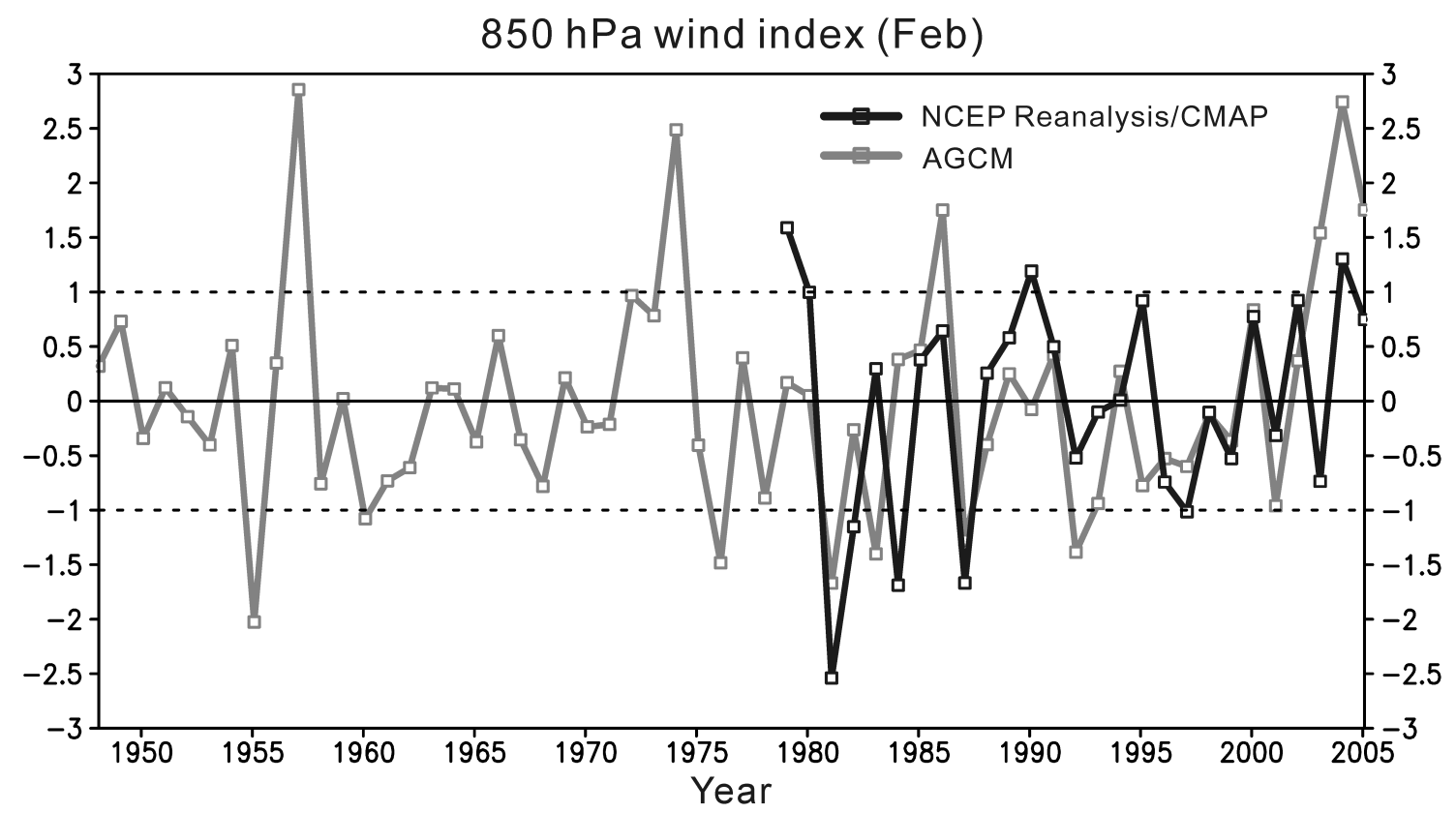

FIG. 2. Time series of February $850 \mathrm{hPa}$ wind index from NCEP/NCAR reanalysis (black curve) and AGCM (grey curve). See text for the definition of wind index, and Fig. 1 for averaging region. 
(a) Positive Phase

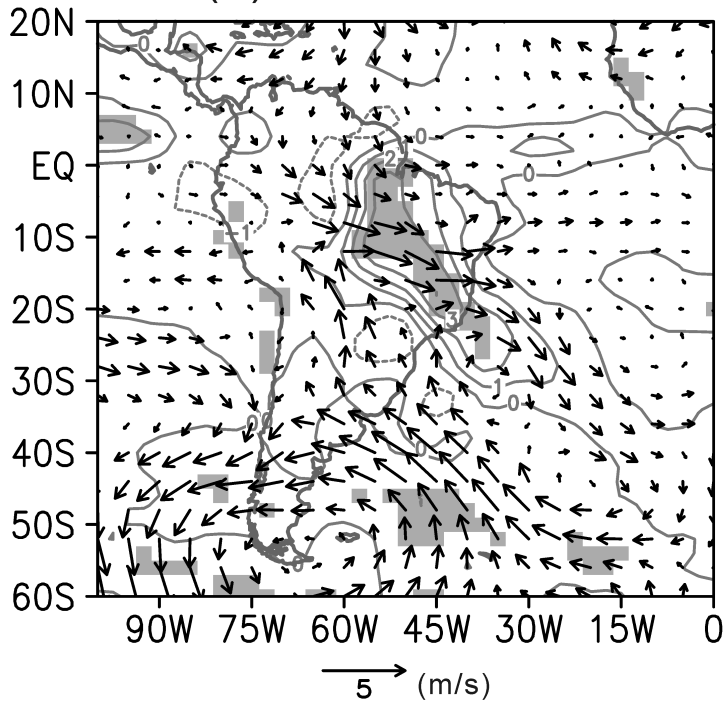

(b) Negative Phase

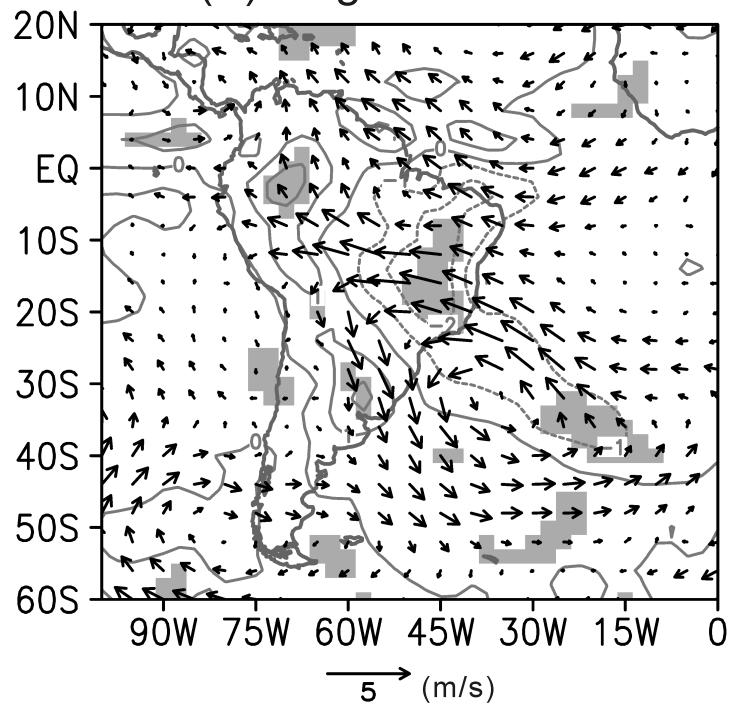

FIG. 3. Composites of February anomalies in precipitation (mm day ${ }^{-1}$, contours) and 850 $\mathrm{hPa}$ wind ( $\mathrm{m} \mathrm{s}^{-1}$, arrows) from CMAP and NCEP/NCAR Reanalysis, during the (a) positive and (b) negative phases based on the $850 \mathrm{hPa}$ wind index. The shaded regions correspond to values of precipitation anomalies that are significant at the $95 \%$ confidence level. The contour interval is $1 \mathrm{~mm} \mathrm{day}^{-1}$. 
(a) Positive Phase

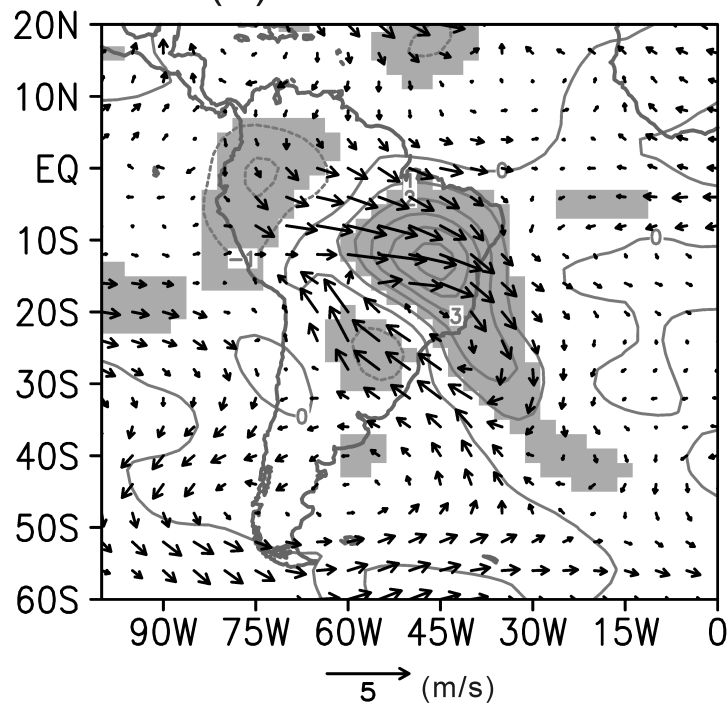

(b) Negative Phase

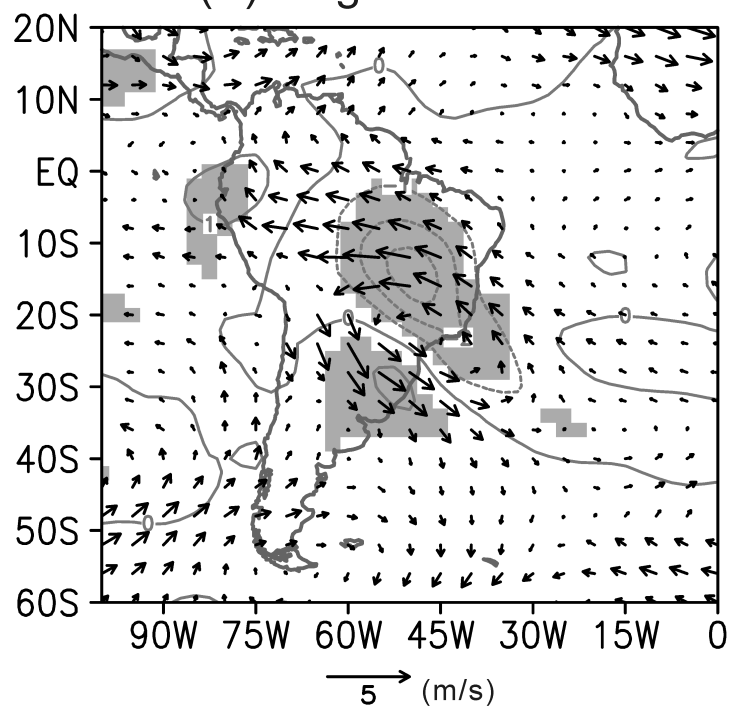

FIG. 4. Same as Fig. 3, except for the simulation. 
(a) Positive Phase

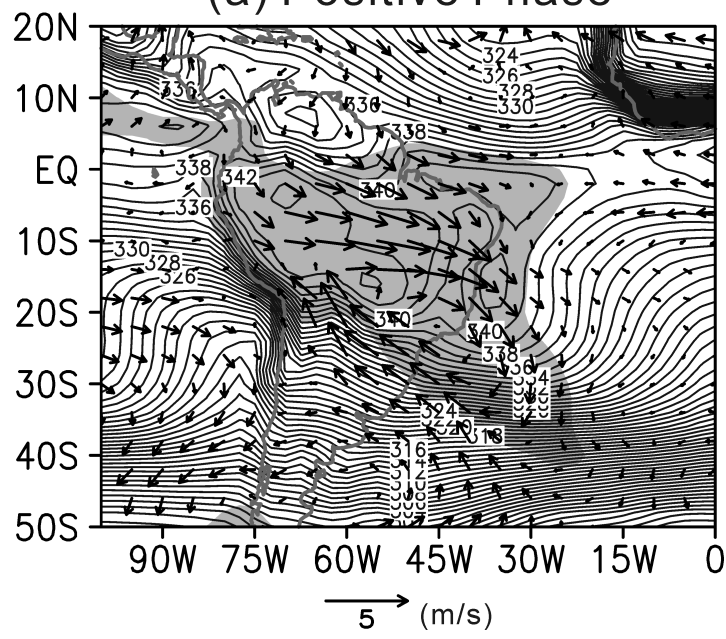

(b) Negative Phase

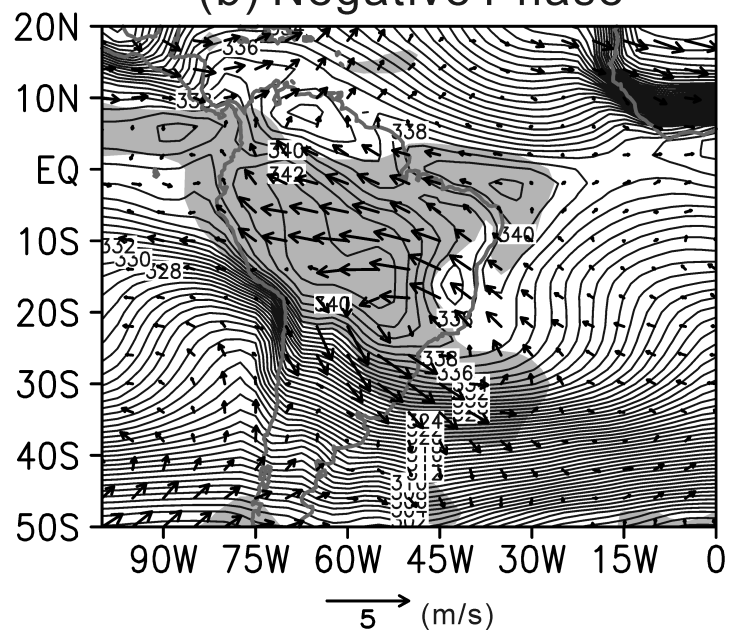

FIG. 5. Composites of simulated February mean moist static energy (K, contours) in the PBL and $850 \mathrm{hPa}$ wind anomalies ( $\mathrm{m} \mathrm{s}^{-1}$, arrows) during the (a) positive and (b) negative phases based on the $850 \mathrm{hPa}$ wind index. Also plotted in (a) and (b) are the shaded areas where composites of simulated February mean precipitation are larger than $4 \mathrm{~mm}^{\mathrm{day}}{ }^{-1}$. The boundary is used as a proxy for the identification of convective margin. 
(a) Positive Phase

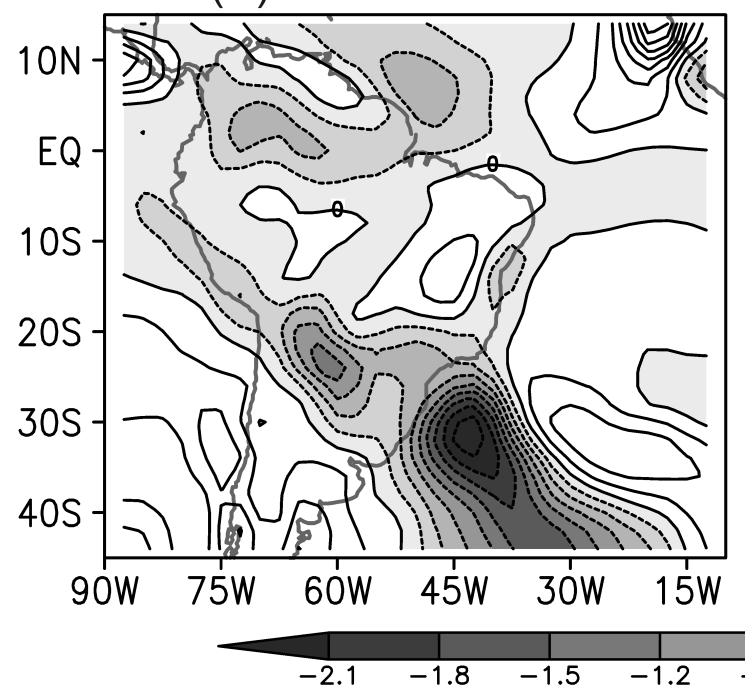

(b) Negative Phase

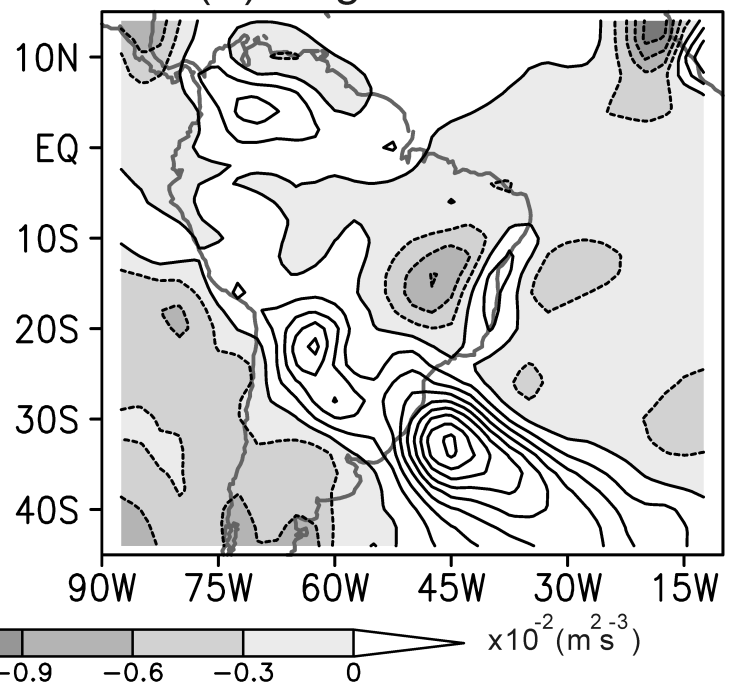

FIG. 6. Composites of simulated February advection of moist static energy by the anomalous flows $\left(-\mathbf{v}^{\prime} \bullet \nabla h_{m}\right)$ in the PBL during the (a) positive and (b) negative phases based on the $850 \mathrm{hPa}$ wind index. The contour interval is $0.003\left(\mathrm{~m}^{2} \mathrm{~s}^{-3}\right)$. 
(a) Positive Phase

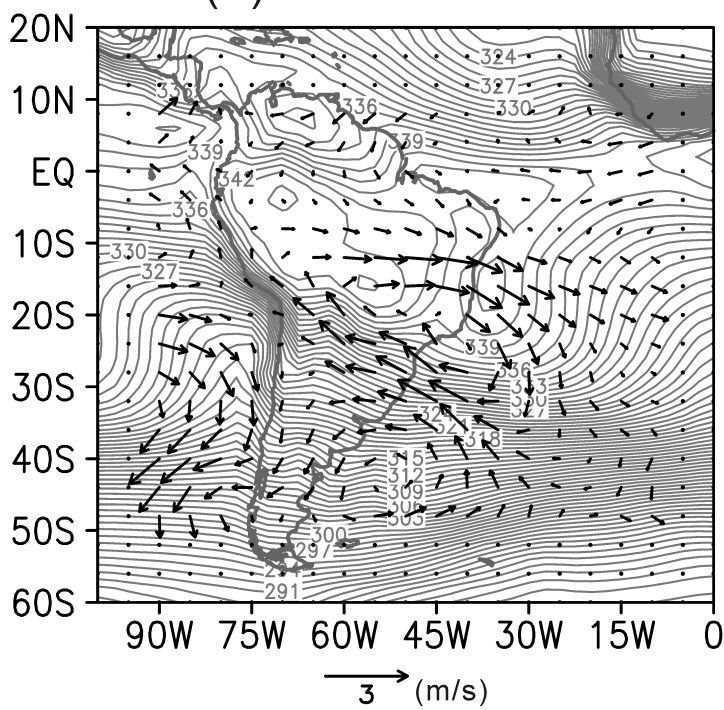

(b) Negative Phase

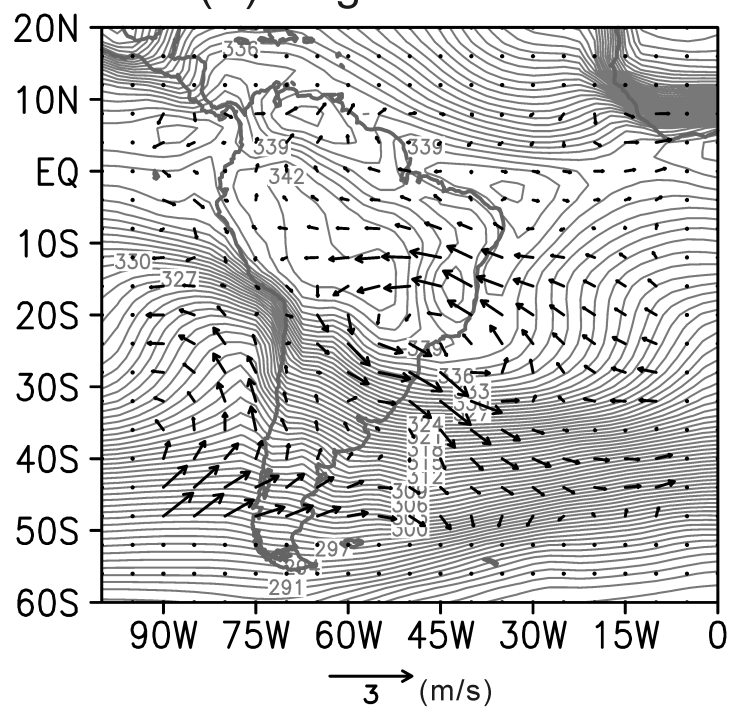

FIG. 7. Composites of simulated February mean moist static energy (K, contours) and non-divergent component of anomalous winds ( $\mathrm{m} \mathrm{s}^{-1}$, arrows) in the PBL during the (a) positive and (b) negative phases of the $850 \mathrm{hPa}$ wind index. See text for more information. 
(a) CONTROL

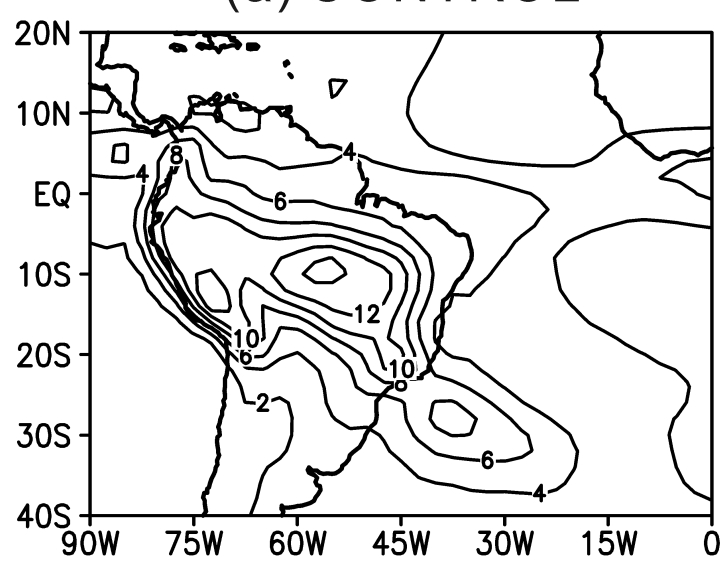

(c) NEGEXP

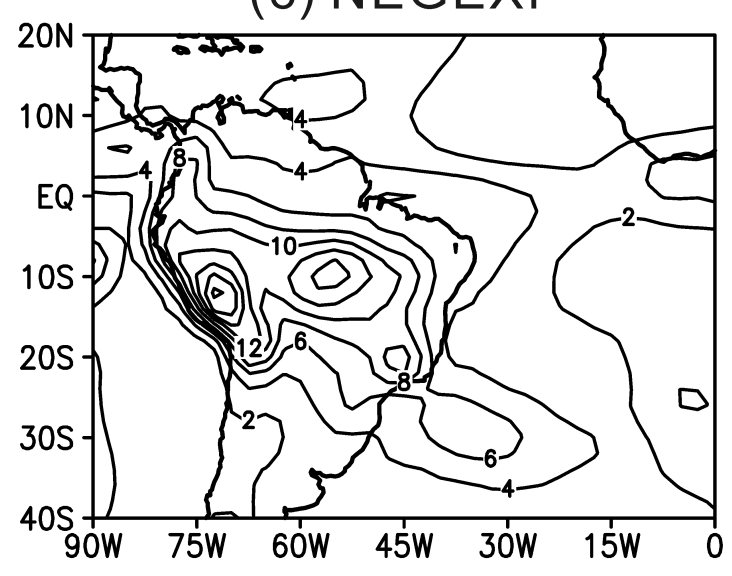

(b) POSEXP

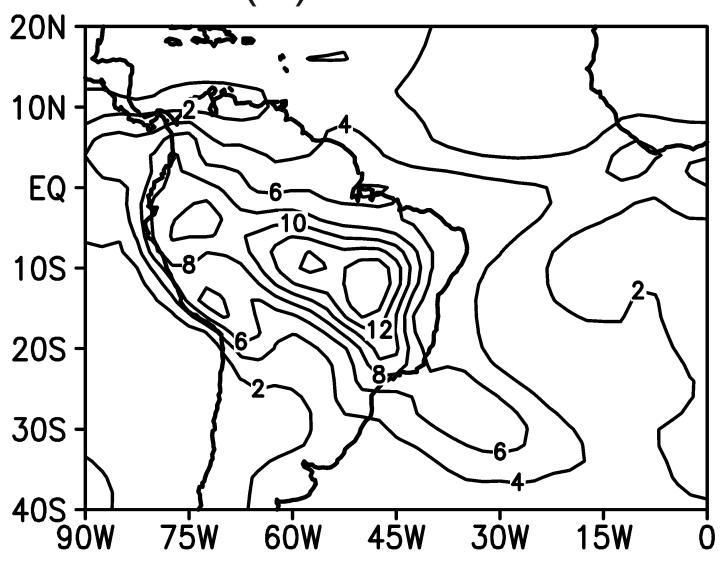

(d) POSEXP-NEGEXP

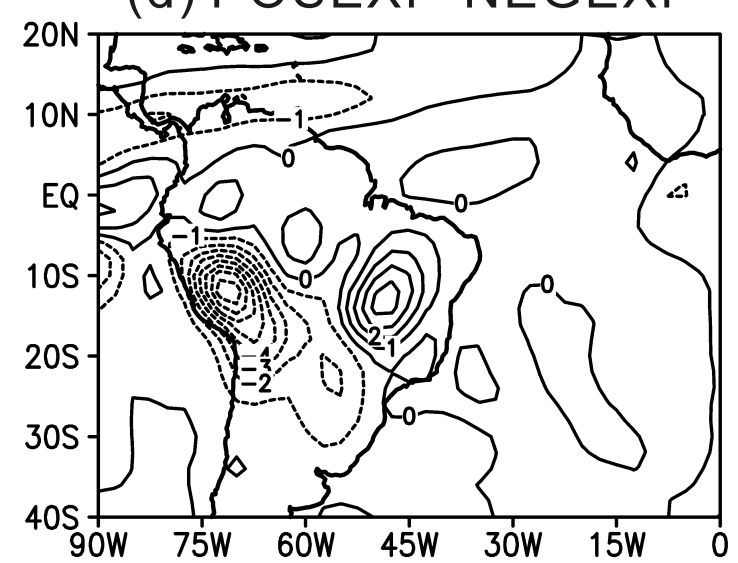

FIG. 8. Mean precipitation $\left(\mathrm{mm} \mathrm{day}^{-1}\right)$ from (a) CONTROL, (b) POSEXP, and (c)

NEGEXP. See text for the experiments description. Also plotted in (d) is the difference of precipitation between (b) and (c). 
(a) POSEXP

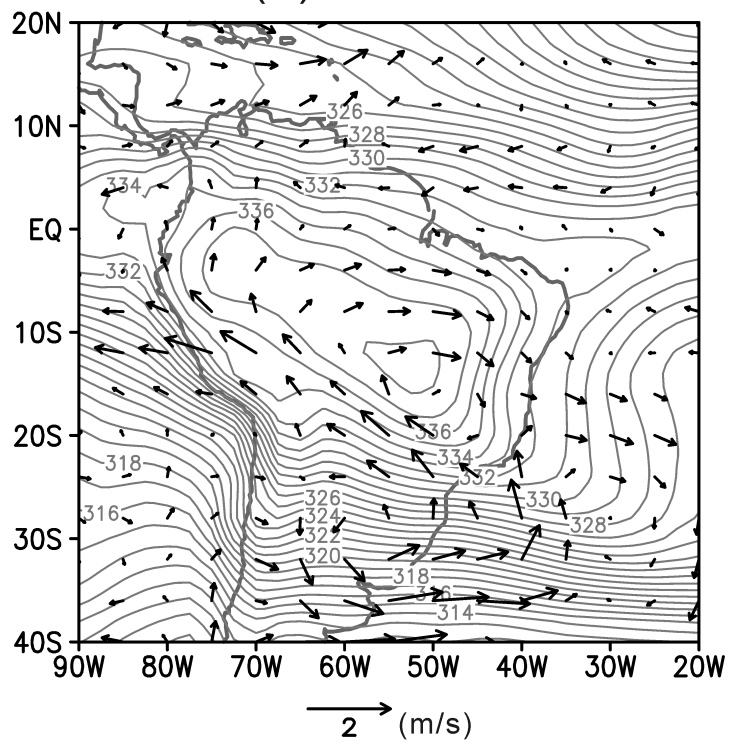

(b) NEGEXP

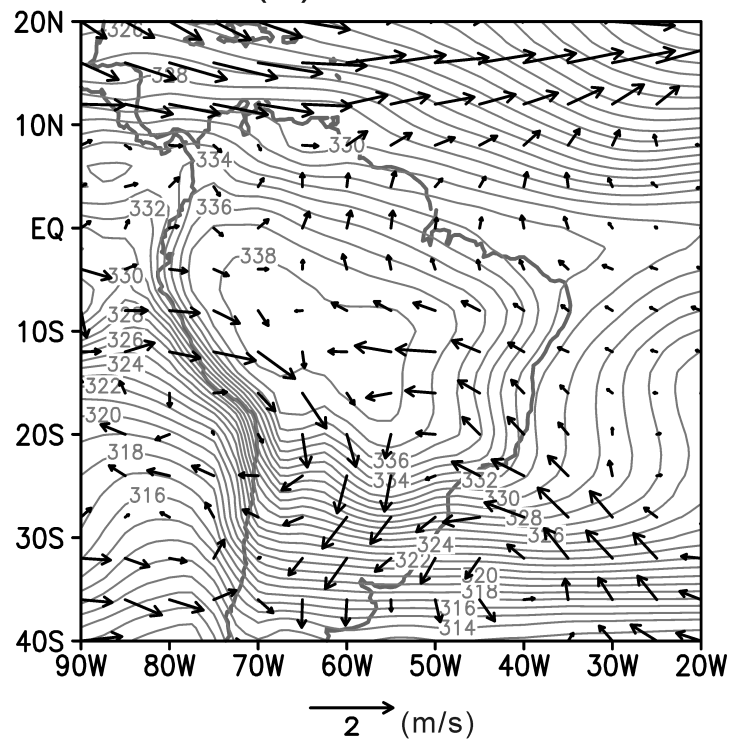

FIG. 9. Mean moist static energy (K, contours) and wind anomalies ( $\mathrm{m} \mathrm{s}^{-1}$, arrows) averaged over the lowest four AGCM levels from (a) POSEXP and (b) NEGEXP. 


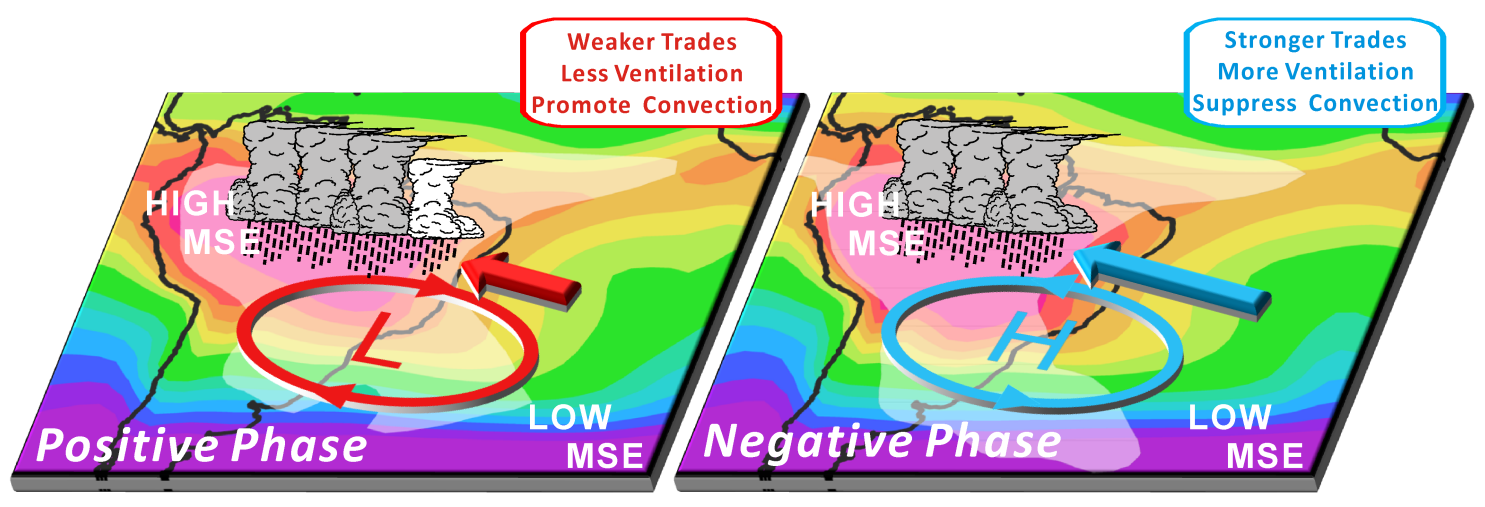

FIG. 10. Schematic diagram of the mechanism for the precipitation variability of the eastern Brazil/SACZ convective margin during positive/negative phases as defined by the intensity of low-level easterly trades. Color shades represent the MSE and white shades represent regions where deep convection occurs. Variability of the low-level easterly trades which are associated with the leading mode of wind variability on interannual time scales can modify the import of low MSE into the convective margin as represented by the red/blue arrow during positive/negative phases, and convection over the convective margin can be modified substantially through the "ventilation" effect. 